\title{
DIAGNÓSTICO DOS MEIOS UTILIZADOS PELA INSTITUIÇÃO DE ENSINO SUPERIOR PARA GERAÇÃO DO CAPITAL SOCIAL REGIONAL
}

\author{
Samuel Martim De Conto ${ }^{1}$, Alexandre André Feil ${ }^{2}$ \\ ${ }^{1}$ samuelcounivates.br \\ 2alexandre.feill@gmail.com
}

\section{Resumo:}

O ambiente concorrencial que as organizações estão enfrentando necessita que a resposta das suas ações tenha como elementos primordiais a receita e o lucro. Entretanto, há organizações de ensino que se configuram como sendo comunitárias, onde o envolvimento com a comunidade é também um elemento primordial. Essa relação com diversos atores possibilita a geração de Capital Social Regional (CSR), aspecto essencial para este tipo de organização. Diante disso, o estudo propõe-se a analisar como o capital social pode ser gerado por uma Instituição de Ensino Superior (IES) comunitária a fim de contribuir para o desenvolvimento regional. Para o desenvolvimento do estudo, o método utilizado foi a abordagem qualitativa e exploratória, utilizando procedimentos técnicos do tipo fontes secundárias, por meio de dois conjuntos de artigos coletados das bases EBSCO e SPELL, levantamentos bibliográficos sobre o assunto, análise de conteúdo e documentos internos da organização estudada. Como resultados desse estudo são apresentados aspectos que demonstram a importância de uma IES comunitária na promoção do CSR, confirmando ainda a sua missão como ator na contribuição do desenvolvimento regional.

Palavras-chave: Capital Social Regional (CSR); Instituição de Ensino Superior comunitária; Vale do Taquari.

\section{DIAGNOSIS OF THE MEANS USED BY THE INSTITUTION OF HIGHER EDUCATION FOR THE GENERATION OF REGIONAL CAPITAL}

\begin{abstract}
:
The competitive environment that organizations are facing requires that the response of their actions have as main elements the revenue and the profit. However, there are educational organizations that are configured as community, where involvement with the community is also a primordial element. This relationship with several actors enables the generation of regional social capital (CSR), an essential aspect for this type of organization. Thus, the study proposes to analyze how social capital can be generated by a Community Higher Education Institution (HEI) in order to contribute to regional development. For the development of the study, the method used was the qualitative and exploratory approach, using technical procedures of the type secondary sources, through two sets of articles collected from the databases EBSCO and SPELL, bibliographical surveys on the subject, content analysis and internal documents Of the organization studied. As results of this study are presented aspects that demonstrate the importance of a community HEI in the promotion of CSR, also confirming its mission as an actor in the contribution of regional development.
\end{abstract}

Keywords: Regional social capital (CSR); Community Higher Education Institution; Vale do Taquari. 


\section{Introdução}

O capital social é essencial, em nível nacional e global, pela promoção de reciprocidade e confiança na economia por meio de interconexões de diversas e distintas formas de capital humano. Neste sentido, Malecki (2012) enfatiza que o capital social compreende uma cultura de interação entre atores, fluindo destes, resultados econômicos produtivos.

A geração de conhecimento e aprendizagem ocorrem por meio do capital social, no qual o conhecimento coletivo é o cerne no processo de inovação, em especial, em organizações (CHEN; REDDING, 2017). Além disso, este capital pode ser considerado um fator que facilita a inovação (MURPHY; HUGGINS; THOMPSON, 2016). Entretanto, estes autores defendem que o capital social não pode ser considerado uma panaceia para aumentar o grau da inovação no âmbito de programas políticos regionais.

As desigualdades, as relações de poder e o excesso de capital social podem ser benéficos no ambiente de inovação e de desenvolvimento regional (CHEN; REDDING, 2017). Portes (2014) defende dois efeitos negativos que podem advir do capital social: a) os benefícios locais oriundos de comunidades com determinado perfil étnico ou religiosos podem ser considerados por outros grupos como exclusão social e econômica; e b) reinvindicações excessivas realizadas sobre atores prósperos de uma determinada comunidade por outras.

Estas questões podem ter relação com a dificuldade de definição do termo capital social, pois apesar da proliferação da ideia ainda não está consolidado (MALECKI, 2012). E outro fator dificultoso vinculado a definição é a interpretação do tema realizado por diversas áreas do conhecimento, tais como a sociologia, economia, administração, contabilidade, entre outros.

Diante destas realidades, Menezes e Carniello (2016) defendem que as Instituições de Ensino Superior (IES) podem ser uma solução para equilibrar os benefícios do capital social a comunidade, pois tende a ser neutra em questões políticas, crenças, idealizações, entre outras. Estudos sobre a relação entre IES e a geração de capital social centram-se na formação do capital social coletivo - tipo bonding e bridging - (AGOSTINI, 2015), avaliação das relações entre as IES e do capital social regional (MENEZES; CARNIELLO, 2016), análise das ações de interação entre a comunidade, IES comunitária e o desenvolvimento regional (PAIM; YAMAGUCHI, 2015), análise da relação entre as universidades e o desenvolvimento econômico (CALDARELLI; CALDARELLI; PERDIGÃO, 2015), exploração da finalidade do capital social regional relativo aos aspectos da inovação (LAURSEN; MASCIARELLI; REICHSTEIN, 2016), entre outros.

Neste contexto, este estudo tem como objetivo geral identificar como o fator capital social é gerado por uma IES a fim de contribuir ao desenvolvimento regional. Este estudo justifica-se na medida em que são identificados os elementos centrais da criação de uma Instituição de Ensino Superior (IES) comunitária, reunindo desde sua fundação os principais atores de uma região (comunidade, governo municipal, igreja, associações), vislumbrando o impacto de suas ações e sua contribuição decisiva no desenvolvimento regional. Neste sentido, uma IES comunitária, além de desempenhar seu papel no ensino, na pesquisa e na extensão, possui no seu cerne a preocupação com as questões da região onde atua, atuando como dinamizadora do desenvolvimento socioeconômico, amparada dessa forma pelo capital social regional. 


\title{
2. Referencial Teórico
}

\subsection{Considerações Iniciais a Respeito de Capital Social}

O termo capital social foi introduzido na literatura em 1916 por Hanifan (1916), porém deste a década 1980 tornou-se um marco, por exemplo, estudos seminais de Bourdieu (1980) e Coleman (1988). A ideia de capital social de Bourdieu (1980) relaciona-se a soma de recursos de um grupo ou individual em relação as redes de relacionamentos institucionais e de Coleman (1988) não pode ser uma propriedade privada de qualquer ator.

A definição do termo capital social carece de consolidação na literatura, apesar de sua utilização e importância, sendo assim, MALECKI (2012) enfatiza três observações em relação a sua definição: a) representa a sobreposição entre as esferas sociais e econômicas da humanidade; b) há distinção na sua presença escassa e na abundante; c) há uma incerteza na escolha da escala ou nível de análise deve ser focada em relação ao nível coletivo ou indivíduo.

As aplicações do capital social possuem indícios ao longo das ciências sociais, por exemplo, no desempenho econômico, educação, governo, crime, saúde e bem estar, entre outros (HALPERN, 2005). O capital social é gerado pela estrutura de relações sociais e pode ser mobilizado para facilitar ações (ADLER; KWON, 2002). Neste sentido, a rede de relações das pessoas é um dos fatores que auxiliam atingir os objetivos e a resolução de problemas.

O capital social facilita a criação de novo capital intelectual e as organizações conduzem ao desenvolvimento de altos níveis de capital social (NAHAPIET; GHOSHAL, 1998). Como resultado dessa criação, as organizações conquistam vantagens competitivas quando desenvolvem e compartilham o capital intelectual, haja vista, esse elemento estar relacionado à geração de capital social.

Num entendimento mais completo a respeito de capital social, Bourdieu (1980, p. 67) menciona que trata-se de um

\begin{abstract}
[...] conjunto de recursos atuais ou potenciais que estão ligados à posse de uma rede durável de relações mais ou menos institucionalizadas de interconhecimento e de inter reconhecimento ou, em outros termos, à vinculação a um grupo, como conjunto de agentes que não somente são dotados de propriedades comuns (passíveis de serem percebidas pelo observador, pelos outros ou por eles mesmos), mas também são unidos por ligações permanentes e úteis.
\end{abstract}

Bourdieu (1980) também destaca que a criação do capital social ocorre por meio das atitudes, concepções e disposições dos indivíduos que pertencem à mesma classe, e neste caso, o volume do capital que uma pessoa ou uma organização possui depende do tamanho da rede de relações que irá mobilizar.

$\mathrm{Na}$ área organizacional a aplicação do conceito de capital social tem influenciado carreiras de sucesso e executivos; trabalhadores na busca por trabalho e no recrutamento de empresas; troca de recursos entre unidades; inovação de produtos; criação de capital intelectual; efetividade na equipe multifuncional; redução de dissoluções de empresas; facilitador de empreendedorismo; formação de start-ups; fortalecimento na relação com fornecedores, formação de redes de cooperação e aprendizagem entre organizações (ADLER; KWON, 2002).

Costa e Costa (2005) mencionam que o capital social deve ser analisado como algo inseparável da estrutura de relações estabelecidas entre os atores, ao contrário do capital físico, onde é possível vê-lo e quantificá-lo. Capital social tem a característica de ser um fator 
intangível, e quanto mais é utilizado, maior será seu valor na interação entre os atores. No âmbito organizacional, o desenvolvimento e a performance econômica da firma por meio das redes de relacionamento constituem a potencialidade de desenvolvimento do capital social (NAHAPIET; GHOSHAL, 1998).

Dessa forma, capital social é a boa vontade disponível para indivíduos ou grupos. Sua origem encontra-se na estrutura e conteúdo das relações sociais do ator. Seu fluxo tem efeito quando a informação, influência e solidariedade se tornam disponíveis para o ator (ADLER; KWON, 2002).

O capital social pode ser classificado em três esferas (WOOLCOCK, 2004): I) capital social de ligação: família, amigos, vizinhos; II) Capital social-ponte: colegas e associados distantes; e III) ligando ao capital social: conexões com pessoas em posições de autoridade. Além desta classificação o capital social também pode ser tipificado pelo nível de agregação (WESTLUND, 2006): a) Nação: culturas nacionais; b) região: cultura e mentalidade regional; c) Local: relações locais; d) Grupo: relações, normas e redes; e e) indivíduo: Comportamento, preferencias, valores, atitudes e opiniões.

\subsection{IES Comunitárias e Capital Social Regional}

O ensino superior Brasileiro, em 2015, era constituído por 2.364 instituições públicas e privadas (INEP, 2015). Embora o governo federal tenha adotado várias políticas com o objetivo de expandir as instituições públicas federais, as instituições privadas representam $88 \%$ do total de IES. Destaca-se ainda na caracterização, que uma instituição pública pode ser municipal, estadual ou federal e as instituições privadas podem ser confessionais, privadas com fins lucrativos e privadas sem fins lucrativos (ABMES, 2011). As IES privadas sem fins lucrativos são denominadas de comunitárias que estão presentes principalmente nos estados do RS e SC.

As IES privadas, além de representar a maior parcela no total de IES brasileiras, também representam aproximadamente $73,7 \%$ do volume total de matrículas nacionais (PEREIRA; MINASI, 2014) tendo papel marcante no processo de desenvolvimento intelectual, tecnológico, econômico e social.

Analisando-se o mercado de atuação das instituições comunitárias, observa-se um aumento da concorrência provocada, em especial, por instituições com baixo investimento em estrutura e manutenção, algumas focadas na economia de escala e deixando de lado a qualidade do ensino, e também exclusivamente mercantilistas. Nesse sentido, as IES comunitárias estão organizadas em associações, como as gaúchas Consórcio das Universidades Comunitárias Gaúchas (COMUNG) e as catarinenses Associação Catarinense das Fundações Educacionais (ACAFE), possibilitando a troca de experiências, o fortalecimento individual das instituições e o aumento da representatividade destas firmas enquanto pertencentes a um setor econômico. Cabe salientar ainda que, de encontro a diversas IES privadas, as comunitárias reinvestem integralmente na atividade o resultado financeiro obtido no período.

As IES comunitárias são reguladas pelo Projeto de Lei da Câmara (PLC) 1/2013, que considera que as universidades comunitárias são instituições que se constituem na forma de associação ou fundação de direito privado, tenham patrimônio pertencente à sociedade civil ou ao poder público, não distribuam sua renda, apliquem integralmente os recursos nas suas atividades e desenvolvam permanentemente ações comunitárias (COMUNG, 2014).

Embora a maioria das IES não tenham em sua missão a preocupação com o desenvolvimento da região de atuação, as IES comunitárias contribuem decisivamente para a melhoria das condições sociais e humanas das pessoas que se relacionam direta e indiretamente. A análise multifacetada das interações entre IES comunitárias e a região pode ser observada na Figura 1. Neste sentido, o capital social pode ser resultante da rede durável de relações institucionalizadas (BOURDIEU, 1980), permitindo a cooperação entre os diferentes grupos 
sociais (FRANCO, 2004), e permitindo que as IES comunitárias criam um novo capital intelectual (NAHAPIET; GHOSHAL, 1998).

Figura 1 - Relação entre IES e a região

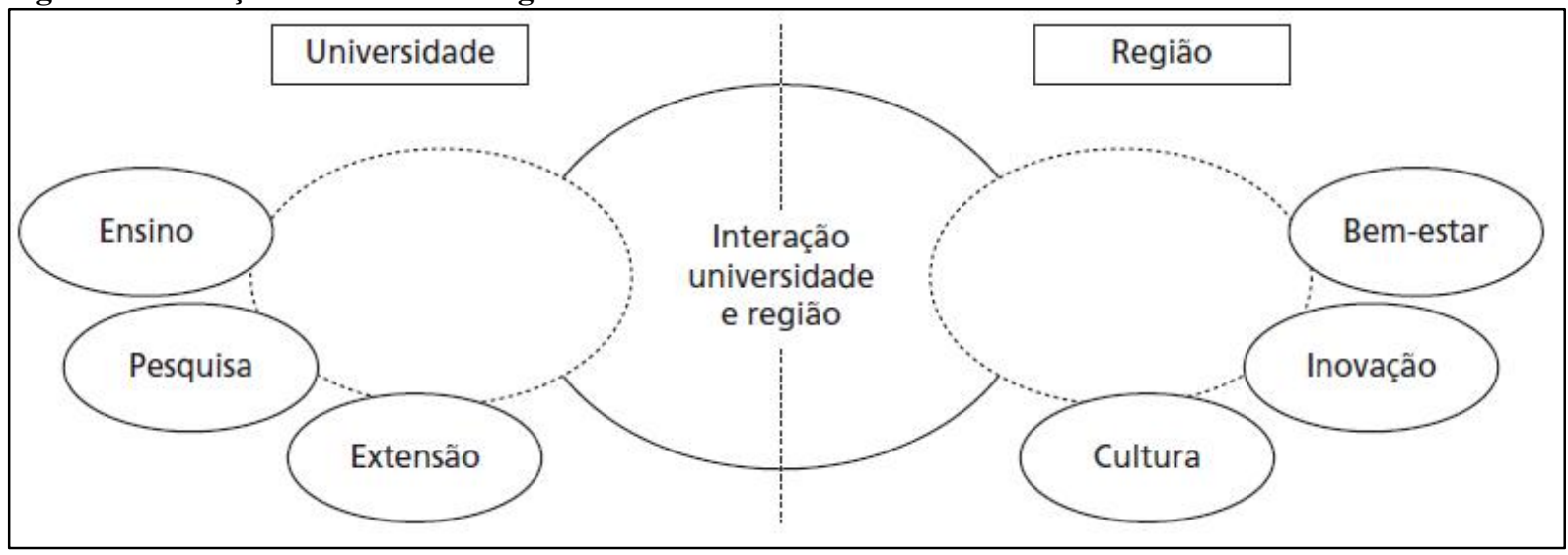

Fonte: Adaptado de Goddard (1999).

A Figura 1 revela um papel tríptico das Universidades, tais como Ensino, Pesquisa e Extensão, e estas interagem com a região de maneira indissociável, integrada e conjunta (GODDARD, 1999). A área central apresenta a interação universidade e região e não pode ser considerada como unidirecional, pois além de ser um fator de influência para a região, esta última também influencia a universidade (YUSUF; NABESHIMA, 2007). A área da região apresenta a maneira pela qual é influencia pelas universidades, os quais podem ocorrer por meio das melhorias do processo de inovação e pela cultura e bem-estar, ou seja, de ampla forma (CALDARELLI; CALDARELLI; PERDIGÃO, 2015).

O capital social regional pode ser descrito como valores e crenças que interagem dentro de uma área geográfica restrita, que induz o comportamento corporativo e a disposição de atitudes colaborativas (GUISO; SAPIENZA; ZINGALES, 2011). Este capital em nível regional facilita o intercâmbio de informações e promove acordos de conhecimentos dentro de uma localização geográfica (LAURSEN; MASCIARELLI; PRENCIPE, 2012).

Os níveis elevados de capital social regional permitem que as organizações tenham acesso fácil a diferentes conjuntos de conhecimentos e de tecnologia (LAURSEN; MASCIARELLI; REICHSTEIN, 2016). A IES comunitária é o ator fundamental para a promoção do capital social regional, haja vista as várias ligações com diferentes atores sociais e as habilidades e competências para identificar, propor e executar ações de melhorias sociais (NAHAPIET; GHOSHAL, 1998).

\section{Procedimentos Metodológicos}

\subsection{Tipo de Pesquisa e Unidade de Análise}

A tipificação desta pesquisa é qualitativa, exploratório, bibliográfica e estudo de caso. A pesquisa qualitativa adere-se pela utilização de informações textuais com base em análise interpretativas. A pesquisa exploratória busca uma compreensão e aprofundamento das interrelações do capital social regional e a IES comunitária, pois há escassa e fragmentada literatura sobre o assunto e o mesmo ainda não está consolidado. A pesquisa bibliográfica realiza um levantamento da literatura existente sobre o tema deste estudo, em especial, de artigo científicos que receberem avaliação cega por pares. $O$ estudo de caso aplica-se a uma IES comunitária comparando paralelamente com as informações advinda da base bibliográfica. 
A unidade de análise localiza-se na região do Vale do Taquari ${ }^{1}$ é formado por 36 municípios, em especial, colonizado por imigrantes italianos e alemães, embora outras etnias também estejam presentes como a portuguesa, a espanhola, a africana, e outras. Esta região é atendida há quase 50 anos com ensino superior e, atualmente, a Univates é uma das IES comunitárias do RS, que tem como uma das principais características a constante inserção regional, bem como a participação da comunidade nos conselhos e nas suas assembleias.

As IES comunitárias por terem relação mais próxima com a comunidade onde atuam, em determinados momentos, são procuradas pela própria comunidade para ser um parceiro no desenvolvimento de projetos de interesse regional. Essas ações são percebidas pela comunidade, como sendo algo que está além do propósito inicial de uma organização de ensino. Dessa forma, o conjunto de ações realizadas que uma instituição de ensino comunitária configura-se como fonte geradora de capital social regional.

O Centro Universitário UNIVATES é uma IES comunitária, localizada no município de Lajeado, no Vale do Taquari, RS. A origem da Instituição ocorreu em 1969 com os cursos de Letras, Economia e Ciências Contábeis. Atualmente, a Univates conta com 12.700 alunos, frequentando aproximadamente 140 cursos de extensão, técnicos, graduação e pós-graduação (Lato e Stricto Sensu).

\subsection{Coleta e Análise dos Dados}

A coleta dos dados ocorreu por meio de levantamento bibliográfico a respeito da temática em português (capital social) e em Inglês (social capital). As bases de dados utilizados relacionam-se a Business Source Elite (EBSCO) e a base Scientific Periodicals Electronic Library (SPELL). A utilização destas bases justifica-se pela qualidade dos papers publicados, sendo que, além disso, a EBSCO possui o cadastro superior a 600 revistas científicas e acima de 350 revistas ativas com revisão de pares. Já a SPELL possui mais de 38.788 documentos, entre artigos e capítulos de livros. Na SPELL foram consultados artigos nacionais e na EBSCO artigos internacionais e os resultados desta consulta está descrita no Quadro 1. O recorte temporal (2009 a 2013) justifica-se pela quantidade de papers publicados nas bases, sendo em número superior aos demais períodos pesquisados.

Quadro 1 - Parâmetros das duas bases de artigos científicos

\begin{tabular}{|l|l|l|}
\hline \multirow{2}{*}{ Parâmetro } & \multicolumn{1}{|c|}{ Base de periódicos } \\
\cline { 2 - 3 } & \multicolumn{1}{|c|}{ EBSCO } & \multicolumn{1}{c|}{ SPELL } \\
\hline Termo de consulta & Capital social; social capital & Capital social \\
\hline Data de publicação & 2009 a 2013 & 2009 a 2013 \\
\hline Bases periódicos & Academic Search Elite; Business & Administração (área de conhecimento) \\
& Source Elite; Regional Business News; & \\
& GreenFILE; Environment Complete; \\
& Human Resources Abstracts; Library, & \\
& Information Science \& Technology \\
& Abstracts; Information Science \& & \\
& Technology Abstracts (ISTA) & \\
\hline Resultado & 654 artigos & 40 artigos \\
\hline Ordenamento & Relevância dos artigos visualizados & Número de downloads realizados \\
\hline
\end{tabular}

Fonte: Elaborado pelos autores.

\footnotetext{
${ }^{1}$ Localizado na região central do RS, tinha em 2012 a população de 332.249 habitantes, a taxa de analfabetismo era de 4,06\% em 2010, o PIB era de R \$ 8,5 bilhões em 2011 e em 2013 as exportações das empresas da região atingiram o montante de U\$ FOB 426.454 .933 (FEE, 2014).
} 
A partir do Quadro 1 foram selecionados 10 artigos científicos de cada base conforme o critério de ordenamento utilizado - relevância dos artigos visualizados para artigos da Base EBSCO e número de downloads realizados para artigos da Base SPELL -, conforme resultado do Quadro 2. Esses critérios de seleção justificam-se pelo fato de que: a) na Base EBSCO foram os dez artigos mais consultados e visualizados no período, e; b) na Base SPELL foram os dez artigos com maior quantidade de downloads no período.

Quadro 2 - Artigos coletados das Bases EBSCO e SPELL

\begin{tabular}{|c|c|}
\hline Base EBSCO & Base SPELL \\
\hline Ansari, Munir e Gregg (2012) & Breitenbach, Froehlich e Brandão (2009) \\
\hline Engelen, Lackoff e Schmidt (2013) & Ducci e Teixeira (2011) \\
\hline Estrin, Mickiewicz e Stephan (2013) & Genari, Macke e Faccin (2012) \\
\hline Gedajlovic et al. (2013) & Monteiro, Regis e Melo (2010) \\
\hline Huang chua et al. (2012) & Paiva Júnior, Fernandes e Almeida (2010) \\
\hline Karahanna e Preston (2013) & Romaniello, Amâncio e Campos (2012) \\
\hline Light e Dana (2013) & Silva, Pereira e Alcântara (2012) \\
\hline Mignon e Mahmoud-jouini (2014) & Wegner e Maehler (2012) \\
\hline Wagner, Beimborn e Weitzel (2014)
\end{tabular}

Fonte: Elaborado pelos autores.

As informações da Instituição foram coletadas por meio do Relatório Anual de Atividades 2013 (UNIVATES, 2013), bem como realização de entrevista com a Pró-reitora de Desenvolvimento Institucional, a fim de sanar dúvidas a respeito da interpretação das ações realizadas. A utilização do Relatório do ano de 2013 justifica-se como sendo o período que a Instituição começou a se preparar para a transformação em universidade, mudança essa que ocorreu no ano de 2017.

Os estudos do Quadro 2 são os selecionados para leitura e tabulação de seus principais resultados. Após a tabulação das principais informações realizou-se a análise de conteúdo caracteriza-se como um procedimento exploratório qualitativo, que para Bardin (2009), é um trabalho exaustivo, que visa aprofundar o entendimento do fenômeno estudado. Ainda conforme Bardin (2009, p. 31) esta análise "[...] é um conjunto de técnicas de análise das comunicações".

As vantagens da utilização da análise de conteúdo em estudos organizacionais relacionam-se a segurança da metodologia, pois poderá ser corrigida se ocorrer alguma falha no estudo; implicação em critérios de categorias para verificações de confiabilidade e validade, com criação de uma estrutura de dados reaplicável; esta metodologia poderá ser utilizada em conjunto com outros métodos para fins de triangulação; e, os custos para elaboração podem ser considerados baixos (DURIAU; REGER; PFARRER, 2007). Após a análise de conteúdo, na sequência, foram elencados os principais resultados encontrados nos estudos e relacionados com a contribuição da IES comunitárias para a geração de capital social.

As principais limitações do método utilizado referem-se à subjetividade na interpretação das informações coletadas, haja vista tratar-se de um estudo qualitativo exploratório, e a não generalização das considerações a respeito dos resultados, haja vista tratar-se de um estudo de caso.

\section{Apresentação e Análise da Situação da IES}

A comparação de resultados de estudos internacionais sobre capital social com as ações e atitudes da IES comunitária relevam que a IES comunitária possui múltiplas interações por 
meio de atitudes e ações que desenvolvem o capital social (QUADRO 3). Os principais atitudes e ações realizadas pela IES comunitária e que estão relacionadas aos estudos internacionais vinculam-se a: a) projetos de extensão, pesquisas; b) participação em comissões e assembleias regionais; c) disciplina institucional de empreendedorismo e incubação de empresas pelo Tecnovates; d) interação entre a Instituição, as empresas, a comunidade, as associações e representações sociais; e, e) as ações e projetos institucionais acessíveis a toda a comunidade.

Quadro 3 - Principal resultado da EBSCO e IES

\begin{tabular}{|c|c|c|}
\hline \multicolumn{2}{|c|}{ Artigos da Base EBSCO } & \multirow{2}{*}{ Situação na IES } \\
\hline Artigo & Principal resultado do estudo & \\
\hline $\begin{array}{l}\text { Ansari, Munir e } \\
\text { Gregg (2012) }\end{array}$ & $\begin{array}{l}\text { A redução da pobreza é uma } \\
\text { questão social, política } \\
\text { econômica. }\end{array}$ & $\begin{array}{l}\text { Realiza ações e atividades sociais objetivando o bem } \\
\text { estar humano, por exemplo, projetos de extensão, } \\
\text { pesquisas, e a participação em projetos de interesse } \\
\text { regional que pode contribuir com a redução da pobreza. }\end{array}$ \\
\hline $\begin{array}{l}\text { Engelen, Lackoff } \\
\text { e Schmidt (2013) }\end{array}$ & $\begin{array}{l}\text { As redes de relacionamentos têm } \\
\text { influência em equipes do topo da } \\
\text { gestão. }\end{array}$ & $\begin{array}{l}\text { As diversas instâncias de decisão estão alinhadas ao } \\
\text { propósito institucional. E há a participação de } \\
\text { integrantes da IES em comissões e assembleias de } \\
\text { representação regional. }\end{array}$ \\
\hline $\begin{array}{l}\text { Estrin, } \\
\text { Mickiewicz e } \\
\text { Stephan (2013) }\end{array}$ & $\begin{array}{l}\text { Empreendedorismo social como } \\
\text { indicador de capital social. }\end{array}$ & $\begin{array}{l}\text { Na disciplina institucional de empreendedorismo os } \\
\text { alunos desenvolvem projetos relacionados a campanha } \\
\text { de doação de sangue e realização de atividades para } \\
\text { deficientes físicos. }\end{array}$ \\
\hline $\begin{array}{l}\text { Gedajlovic et al. } \\
(2013) \\
\text { Light e Dana } \\
(2013)\end{array}$ & $\begin{array}{l}\text { Capital social como impulsionador } \\
\text { do empreendedorismo. }\end{array}$ & $\begin{array}{l}\text { Além da disciplina institucional de } \\
\text { Empreendedorismo, também há a incubadora de } \\
\text { empresas (INOVATES) que objetiva oferecer } \\
\text { condições que novos negócios sejam colocados no } \\
\text { mercado. Além disso, o Parque Tecnológico que visa } \\
\text { estimular a inovação na área de alimentos e ambiente. }\end{array}$ \\
\hline $\begin{array}{l}\text { Huang chua et al. } \\
\text { (2012) }\end{array}$ & $\begin{array}{l}\text { Introdução de normas que } \\
\text { beneficiem o capital social e } \\
\text { inibindo normas prejudiciais ao seu } \\
\text { desenvolvimento. }\end{array}$ & $\begin{array}{l}\text { A missão e a visão da Instituição contemplam também } \\
\text { aspectos sociais, tendo a preocupação com a região. }\end{array}$ \\
\hline $\begin{array}{l}\text { la e } \\
2013)\end{array}$ & $\begin{array}{l}\text { Desenvolvimento do capital social } \\
\text { é um processo socialmente } \\
\text { complexo, com relações enraizadas } \\
\text { de dependência e esforços para o } \\
\text { seu desenvolvimento. }\end{array}$ & $\begin{array}{l}\text { A constante interação entre a Instituição, as empresas, } \\
\text { a comunidade, as associações e representações sociais } \\
\text { constitui-se num importante mecanismos de } \\
\text { desenvolvimento do capital social na região. }\end{array}$ \\
\hline $\begin{array}{l}\text { Mignon e } \\
\text { Mahmoud-Jouini } \\
(2014)\end{array}$ & $\begin{array}{l}\text { A gestão de equipes contribui para } \\
\text { o desenvolvimento de valores de } \\
\text { coesão, lealdade e responsabilidade } \\
\text { coletiva. }\end{array}$ & $\begin{array}{l}\text { A preocupação da alta gestão é no sentido de seguir e } \\
\text { atender aos princípios institucionais. }\end{array}$ \\
\hline $\begin{array}{l}\text { Wagner, } \\
\text { Beimborn e } \\
\text { Weitzel (2014) }\end{array}$ & $\begin{array}{l}\text { A estratégia deve estar alinhada } \\
\text { desde o nível executivo até o } \\
\text { operacional. }\end{array}$ & $\begin{array}{l}\text { Os colaboradores estão alinhados com os princípios } \\
\text { institucionais, tendo a responsabilidade e a } \\
\text { preocupação em movimentar uma IES comunitária. }\end{array}$ \\
\hline $\begin{array}{l}\text { Zhu e Thomas } \\
\text { (2013) }\end{array}$ & $\begin{array}{l}\text { Diferentes grupos sociais devem ter } \\
\text { igual acesso para o } \\
\text { desenvolvimento do capital social. }\end{array}$ & $\begin{array}{l}\text { As ações e projetos institucionais estão acessíveis a } \\
\text { toda a comunidade acadêmica. Além disso, há projetos } \\
\text { que beneficiam pessoas carentes da comunidade, por } \\
\text { meio de bolsas de estudo, projetos de extensão e ações } \\
\text { sociais. }\end{array}$ \\
\hline
\end{tabular}

Fonte: Elaborado pelos autores.

A comparação de resultados nacionais relacionados ao capital social com as ações e atitudes da IES comunitária revelam os principais aspectos relacionados a: a) ampla rede de relacionamentos por meio dos empreendedores; b) sustentado por três dimensões: cognitiva, relacional e estrutural; c) relações de amizades entre comunidade e IES comunitária; d) 
processo de inovação e empreendedoras tecnológicas; e) interações entre governos e região; f) ampliação e inovação do conhecimento (QUADRO 4).

Quadro 4 - Principal resultado da SPELL e IES

\begin{tabular}{|c|c|c|}
\hline \multicolumn{2}{|r|}{ Artigos da Base SPELL } & \multirow{2}{*}{ Situação na IES } \\
\hline Artigo & Principal resultado & \\
\hline $\begin{array}{l}\text { Breitenbach, } \\
\text { Froehlich e } \\
\text { Brandão (2009) }\end{array}$ & $\begin{array}{l}\text { Ações iniciadas localmente (de baixo para } \\
\text { cima) podem ser fruto de um processo mais } \\
\text { complexo e que têm o capital empresarial } \\
\text { como coordenador. }\end{array}$ & $\begin{array}{l}\text { Diversas ações e projetos regionais são } \\
\text { coordenados e iniciados pela Instituição. }\end{array}$ \\
\hline $\begin{array}{l}\text { Ducci e Teixeira } \\
(2011)\end{array}$ & $\begin{array}{l}\text { Redes sociais utilizadas pelos } \\
\text { empreendedores na obtenção de recursos, } \\
\text { influindo na construção do capital social, nas } \\
\text { fases de criação e de desenvolvimento de } \\
\text { novos negócios. }\end{array}$ & $\begin{array}{l}\text { A estrutura da incubadora de empresas } \\
\text { possibilita que os empreendedores possam } \\
\text { aproveitar os canais institucionais para } \\
\text { viabilizar, desenvolver e ampliar seu } \\
\text { negócio. }\end{array}$ \\
\hline $\begin{array}{l}\text { Ferraz, Gobb e } \\
\text { Lima (2011) } \\
\text { Genari, Macke e } \\
\text { Faccin (2012) }\end{array}$ & $\begin{array}{l}\text { Capital social sustentado por três dimensões: } \\
\text { Dimensão cognitiva (valores de confiança, } \\
\text { de solidariedade, de qualidade, de inovação } \\
\text { e de crescimento); dimensão relacional } \\
\text { (laços de cooperação e confiança); dimensão } \\
\text { estrutural (avanços institucionais). }\end{array}$ & $\begin{array}{l}\text { As três dimensões estão presentes na } \\
\text { Instituição: a cognitiva, com a confiança que } \\
\text { a comunidade tem em relação à Instituição, } \\
\text { além da preocupação com os problemas } \\
\text { regionais e a proposição de ações de } \\
\text { melhoria; a relacional, com a sociedade } \\
\text { demandando ações e projetos da Instituição, } \\
\text { e esta, atendendo dentro das condições que } \\
\text { são possíveis; a estrutural, com a } \\
\text { coordenação de diversas ações institucionais } \\
\text { e de melhoria das condições sociais. }\end{array}$ \\
\hline $\begin{array}{l}\text { Monteiro, Regis e } \\
\text { Melo (2010) }\end{array}$ & $\begin{array}{l}\text { Os laços de amizade formam uma rede em } \\
\text { que há troca de informações entre os atores. }\end{array}$ & $\begin{array}{l}\text { O COMUNG tem como objetivo viabilizar } \\
\text { um processo integrativo resultando no } \\
\text { fortalecimento individual das instituições e } \\
\text { no consequente favorecimento da } \\
\text { comunidade universitária do RS e da } \\
\text { sociedade gaúcha como um todo. }\end{array}$ \\
\hline $\begin{array}{l}\text { Paiva júnior, } \\
\text { Fernandes e } \\
\text { Almeida }(2010)\end{array}$ & $\begin{array}{l}\text { As iniciativas de inovação e } \\
\text { compartilhamento de práticas criativas entre } \\
\text { os integrantes das redes sociais podem } \\
\text { representar uma importante fonte de } \\
\text { negócios para as pequenas e médias } \\
\text { empresas. }\end{array}$ & $\begin{array}{l}\text { As ações e projetos desenvolvidos pela } \\
\text { incubadora de empresas e o parque } \\
\text { tecnológico objetivam potencializar as } \\
\text { iniciativas empreendedoras e de inovação. }\end{array}$ \\
\hline Prates (2009) & $\begin{array}{l}\text { O capital social constitui um recurso } \\
\text { estratégico de ação coletiva voltada para a } \\
\text { produção de bens coletivos internos, tais } \\
\text { como ajuda mútua, participação coletiva, } \\
\text { prestatividade e participação no orçamento } \\
\text { participativo. }\end{array}$ & $\begin{array}{l}\text { Internamento, todos os setores da Instituição } \\
\text { elaboram e gerenciam seu orçamento anual. } \\
\text { Externamente, a Univates atua como ator } \\
\text { regional no fortalecimento do Conselho } \\
\text { Regional de Desenvolvimento do Vale do } \\
\text { Taquari. }\end{array}$ \\
\hline $\begin{array}{l}\text { Romaniello, } \\
\text { Amâncio e } \\
\text { Campos (2012) }\end{array}$ & $\begin{array}{l}\text { Os indicadores confiança, cooperação e } \\
\text { participação são utilizados para identificar o } \\
\text { capital social. }\end{array}$ & $\begin{array}{l}\text { A comunidade tem confiança na Instituição, } \\
\text { esta por sua vez, coopera e participa nos } \\
\text { projetos sociais regionais. }\end{array}$ \\
\hline $\begin{array}{l}\text { Silva, Pereira e } \\
\text { Alcântara (2012) }\end{array}$ & $\begin{array}{l}\text { Capital social no contexto sociopolítico, } \\
\text { econômico e cultural diz respeito às } \\
\text { transformações que vêm modificando as } \\
\text { relações entre cidadãos e governo, e de } \\
\text { governos para com os cidadãos. }\end{array}$ & $\begin{array}{l}\text { Vários projetos que a Instituição coopera e } \\
\text { desenvolve têm a parceria com governos de } \\
\text { todas as esferas. }\end{array}$ \\
\hline $\begin{array}{l}\text { Wegner e Maehler } \\
\text { (2012) }\end{array}$ & $\begin{array}{l}\text { O capital social e a capacidade absortiva das } \\
\text { empresas são fatores importantes para } \\
\text { ampliar a inovação e o desempenho } \\
\text { financeiro e não-financeiro das empresas. }\end{array}$ & $\begin{array}{l}\text { A possibilidade de surgimento de novos } \\
\text { negócios no ambiente universitário } \\
\text { possibilita absorção de conhecimento } \\
\text { científico e a promoção de inovação. }\end{array}$ \\
\hline
\end{tabular}


Fonte: Elaborado pelos autores.

Os resultados apontam que as ações e atitudes da IES comunitária são eloquentes com os relevantes estudos coletados da EBSCO e da SPELL. Nota-se uma ampla gama de relacionamentos e interações relativas ao capital social, o que difere do estudo de Menezes e Carniello (2016), pois admitem que o capital social da IES mineira analisada é baixa e prioritariamente estrutural. A IES comunitária possui um impacto positivo no desenvolvimento regional, por exemplo, em relação ao nível de conhecimento, inovação, participação, entre outros, na medida que realizam vínculos e compromissos consistentes e duradouros, o que corrobora com Rolim e Serra (2009). Neste interim, as IES são atores regionais essenciais para o efetivo desenvolvimento da sociedade.

O capital social pode sofrer desvalorização caso não sofre um contínuo processo de renovação, sendo assim, uma região com elevado capital social regional na atualidade pode ser pobre no futuro caso não mantido ativamente, este apontamento também é evidenciado por Chen e Redding (2017). Neste sentido, a IES comunitária deste estudo deve manter as ações e atitudes e além disso, aprimorá-las continuamente, pois na medida que as necessidades dos atores são satisfeitas outras tornam-se visíveis no lugar daqueles.

A ideia de capital social, conforme os resultados, pode ser criado, mas sua mensuração é complexa, também defendido por Karahanna e Preston (2013) e Breitenbach, Froehlich e Brandão (2009). Nota-se que a geração de capital social em uma determinada região possui uma certa personalidade regional o que dificulta sua replicação em outras regiões, sendo assim, Chen e Redding (2017) defendem que o capital social possui características únicas e regionalmente específico.

As relações sociais que os atores mantêm possibilitam potencializar o recurso do capital social, amparado pelos princípios da confiança mútua, da cooperação, da responsabilidade no desenvolvimento das ações, da proposição de melhorias que contemplam a comunidade regional e da preocupação constante dos aspectos econômicos, sociais, políticos e ambientais.

Em suma, uma IES comunitária como foi o caso empírico, exemplifica a atuação de um ator na promoção do desenvolvimento de uma região, interagindo com demais atores, reafirmando a sua missão desde quando foi concebida, potencializando as forças de cooperação, solidariedade e comunitária, preocupando-se com os problemas e buscando subsídios para a sua resolução, ampliando os horizontes e as possibilidades, fomentando novos conhecimentos, ideias e tecnologias, e sobretudo, reforçando a necessidade de utilizar esforços conjuntos na busca de melhores condições de vida das pessoas.

\section{Considerações Finais}

Este estudo objetivou analisar como uma Instituição de Ensino Superior (IES) contribui para a geração de capital social numa região. A preocupação com a região onde uma IES comunitária está inserida é elemento essencial deste tipo de organização. Embora seja de conhecimento geral que as organizações vislumbram o lucro como sendo o objetivo principal, devendo ser buscado de todas as maneiras, existem organizações em que este elemento é consequência das ações realizadas. A sustentabilidade financeira deve ser uma meta para as IES comunitárias, mas sem esquecer o envolvimento social com a região e a participação em ações e projetos de interesse social.

É a partir das inúmeras interações com a região que uma IES comunitária potencializa o CSR, tornando-se uma experiência única e impossível de ser copiada. Cada ação executada é resultante de esforços conjuntos, realizadas de maneira automática, sem a preocupação com o retorno imediato, ao contrário, com a expectativa de promover o desenvolvimento de uma região, gerando e usufruindo das melhorias sociais. 
Com base na análise realizada, percebem-se várias ações da IES no sentido de contribuir para a geração de capital social interna e externamente. Conforme o Quadro 3, é possível afirmar que a Instituição atende seu propósito institucional, coordenando e desenvolvendo várias ações de desenvolvimento regional, resultando na geração de capital social regional (CSR) no ambiente social, econômico, político, ambiental e humano.

O interesse pela temática do capital social tem aumentado nos últimos anos, haja vista a ocorrência de inúmeras reconfigurações institucionais, produtivas e organizacionais, objetivando potencializar o crescimento de suas atividades e ampliar as relações entre os atores envolvidos. Nesse caso, menciona-se a importância de prosseguir na discussão desta temática, sobretudo nos resultados positivos proporcionados pela interação entre os atores, resultando em maior dinamismo e desenvolvimento do ambiente. Não se pretendia esgotar a discussão em torno do tema, mas sim apresentar uma experiência de envolvimento organizacional com a comunidade, promovendo a partir desta interação o capital social regional.

\section{Referências}

ASSOCIAÇÃO BRASILEIRA DE MANTENEDORAS DE ENSINO SUPERIOR - ABMES. Números do Ensino Superior Privado no Brasil. 2011. Disponível em:

$<$ http://www.abmes.org.br/abmes/publicacao/detalhe/id/52>. Acesso em: 12 jul. 2014.

ADLER, P. S.; KWON, S. W. Social Capital: prospects for a new concept. Academy of Management Review, v. 27, n. 1, p. 14-40, 2002.

AGOSTINI, C. Desenvolvimento regional sustentável: a formação de capital social dos tipos "bonding" e "bridging" no Vale do Taquari. Revista Estudo \& Debate, v. 22, n. 1, p. 27-41, 2015.

ANSARI, S.; MUNIR, K.; GREGG, T. Impact at the 'Bottom of the Pyramid': The Role of Social Capital in Capability Development and Community Empowerment. Journal of Management Studies, v. 49, n. 4, p. 813-842, 2012.

BARDIN, L. Análise de conteúdo. Lisboa, Edições 70, 2009.

BOURDIEU, P. O capital social - notas provisórias. In: NOGUEIRA, M. A.; CATANI, A. (Orgs.) Pierre Bourdieu: escritos de educação. Capítulo III. Petrópolis, RJ: Vozes, 1998.

BREITENBACH, R.; FROEHLICH, J. M.; BRANDÃO, J. B. Estratégia emergencial reativa de desenvolvimento local: mobilização social para intensificação da produção leiteira.

Desenvolvimento em Questão, v. 7, n. 13, p. 129-156, 2009.

CALDARELLI, C. E.; CALDARELLI, M. R. G.; PERDIGÃO, C. Instituições de ensino superior e desenvolvimento econômico: o caso das universidades estaduais paranaenses. Planejamento e políticas públicas, n. 44, p. 85-112, 2015.

CHEN, K. C.; REDDING, G. Collaboration and opportunism as a duality within social capital: a regional ethnic Chinese case study. Asia Pacific Business Review, p. 1-21, 2017. 
COLEMAN, J. S. Social capital in the creation of human capital. American journal of sociology, v. 94, p. 95-120, 1988.

CONSÓRCIO DAS UNIVERSIDADES COMUNITÁRIAS GAÚCHAS - COMUNG. Presidente Dilma sanciona lei que reconhece as Universidades Comunitárias. Disponível em: <http://www.comung.org.br/noticia?id=220>. Acesso em: 15 jan. 2014.

COSTA, A. B.; COSTA, B. M. Cooperação e capital social em arranjos produtivos locais. Disponível em: $<$ http://www.anpec.org.br/encontro2005/artigos/A05A113.pdf $>$. Acesso em: 20 jul. 2014.

DUCCI, N. P. C.; TEIXEIRA, R. M. As redes sociais dos empreendedores na formação do capital social: um estudo de casos múltiplos em municípios do norte pioneiro no estado do Paraná. Cadernos EBAPE.BR, v. 9, n. 4, p. 967-997, 2011.

DURIAU, V. J.; REGER, R. K.; PFARRER, M. D. A Content Analysis of the Content Analysis Literature in Organization Studies: Research Themes, Data Sources, and Methodological Refinements. Organizational Research Methods, v. 10, n. 1, p. 5-34, 2007.

ENGELEN, A.; LACKOFF, F.; SCHMIDT, S. How Can Chief Marketing Officers Strengthen Their Influence? A Social Capital Perspective Across Six Country Groups. Journal of International Marketing, v. 21, n. 4, p. 88-109, 2013.

ESTRIN, S.; MICKIEWICZ, T.; STEPHAN, U. Entrepreneurship, Social Capital, and Institutions: Social and Commercial Entrepreneurship Across Nations. Entrepreneurship: Theory \& Practice, v. 37, n. 3, p. 479-504, 2013.

FUNDAÇÃO DE ECONOMIA E ESTATÍSTICA - FEE. Dados socioeconômicos. Disponível em: $<$ http://www.fee.rs.gov.br/perfil-socioeconomico/coredes/detalhe/?corede= Vale+do+Taquari $>$. Acesso em: 25 jul. 2014.

FERRAZ, S. F. S.; GOBB, R. L.; LIMA, T. C. B. Teoria do Capital Social: um estudo no cluster moveleiro de Marco (CE). Contextus - Revista Contemporânea de Economia e Gestão, v. 9, n. 2, p. 79-95, 2011.

FRANCO, A. Capital social e desenvolvimento local. Disponível em: $<$ http://empreende.org.br/artigos.htm>. Acesso em: 20 jul. 2014.

GEDAJLOVIC, E.; HONIG, B.; MOORE, C. B.; PAYNE, G. T.; WRIGHT, M. Social Capital and Entrepreneurship: A Schema and Research Agenda. Entrepreneurship: Theory \& Practice, v. 37, n. 3, p. 455-478.

GENARI, D.; MACKE, J.; FACCIN, K. Mensuração do capital social organizacional em redes de indústrias vitivinícolas brasileiras. BASE - Revista de Administração e Contabilidade da UNISINOS, v. 9, n. 1, p. 53-67, 2012.

GODDARD, J. B. Universities and regional development: an overview. In: GRAY, H. (Org.). Universities and the creation of wealth. Milton Keynes: Open University Press, 1999. 
GUISO, L.; SAPIENZA, P.; ZINGALES, L. Civic capital as the missing link. In: JESS BENHABIB, A. B.; MATTHEW O. J. (Org.). Handbook of Social Economics, NorthHolland, Amsterdam, 2011. p. 417-480.

HALPERN, D. Social Capital. Polity. Cambridge. 2005.

HANIFAN, L. J. The rural school community center. Annals of the American Academy of Political and Social Science, v. 67, p. 130-138, 1916.

HUANG CHUA, C.; LIM, W. K.; SOH, C.; KIEN SIA, S. 2012. Enacting clan control in complex it projects: a social capital perspective. MIS Quarterly, v. 36, n. 2, p. 577-600, 2012.

INSTITUTO NACIONAL DE ESTUDOS E PESQUISAS EDUCACIONAIS ANÍSIO TEIXEIRA - INEP. Sinopse da Educação Superior 2015. Disponível em:

$<$ http://download.inep.gov.br/informacoes_estatisticas/sinopses_estatisticas/sinopses_educaca o_superior/sinopse_educacao_superior_2015.zip>. Acesso em: 15 abr. 2017.

KARAHANNA, E.; PRESTON, D. S. The Effect of Social Capital of the Relationship Between the CIO and Top Management Team on Firm Performance. Journal of Management Information Systems, v. 30, n. 1, p. 15-56, 2013.

LAURSEN, K.; MASCIARELLI, F.; REICHSTEIN, T. A matter of location: the role of regional social capital in overcoming the liability of newness in R\&D acquisition activities. Regional Studies, v. 50, n. 9, p. 1537-1550, 2016.

LAURSEN, K.; MASCIARELLI, F.; PRENCIPE, A. Trapped or spurred by the home region: the effects of potential social capital on involvement in foreign markets for goods and technology. Journal of International Business Studies, v. 43, p. 783-807, 2012.

LIGHT, I.; DANA, L. P. Boundaries of Social Capital in Entrepreneurship. Entrepreneurship: Theory \& Practice, v. 37, n. 3, p. 603-624, 2013.

MALECKI, E. J. Regional social capital: why it matters. Regional Studies, v. 46, n. 8, p. 1023-1039, 2012.

MENEZES, D. B.; CARNIELLO, M. F. A Participação das Instituições de Ensino Superior de Mineiros Enquanto Agências de Fomento de Capital Social no Desenvolvimento Regional. Revista de Ensino, Educação e Ciências Humanas, v. 17, n. 1, p. 30-36, 2016.

MIGNON, S.; MAHMOUD-JOUINI, S. B. Social capital and human resource management in sustainable family business. International Management, v. 18, n. 3, p. 82-95, 2014.

MONTEIRO, M. R. M. B.; REGIS, H. P.; MELO, P. T. N. B. Redes sociais: o caso dos confeccionistas do APL de Santa Cruz do Capibaribe-PE. Revista de Negócios, v. 15, n. 4, p. 49-65, 2010.

MURPHY, L.; HUGGINS, R.; THOMPSON, P. Social capital and innovation: A comparative analysis of regional policies. Environment and Planning C: Government and Policy, v. 34, n. 6, p. 1025-1057, 2016. 
NAHAPIET, J.; GHOSHAL, S. Social Capital, Intelectual capital and the organizational advantage. Academy of Management Review, v. 23, n. 2, p. 242-266, 1998.

PAIVA JÚNIOR, F. G.; FERNANDES, N. C. M.; ALMEIDA, L. F. L. A competência de relacionamento contribuindo para o desenvolvimento de capital social da empresa de base tecnológica. Revista de Negócios, v. 15, n. 1, p. 11-28, 2010.

PAIM, J. Q.; YAMAGUCHI, C. K. Papel das Universidades Comunitárias de Ensino Superior de Santa Catarina para o Desenvolvimento Regional. In: XV MOSTRA DE INICIAÇÃO CIENTÍFICA, PÓS GRADUAÇÃO, ENSINO, PESQUISA E EXTENSÃO. Programa de pós graduação em administração UCS, 11., 2015. Anais... Caxias do Sul: RS, 2015.

PEREIRA, A. M.; MINASI, L. F. Um panorama histórico da política de formação de professores no Brasil. Revista de Ciências Humanas, v. 15, n. 24, p. 7-19, 2014.

PORTES, A. Downsides of social capital. Proceedings of the National Academy of Sciences, v. 111, n. 52, p. 18407-18408, 2014.

PRATES, A. A. P. Redes sociais em comunidades de baixa renda: os efeitos diferenciais dos laços fracos e dos laços fortes. Revista de Administração Pública, v. 43, n. 5, p. 1117-1146, 2009.

ROLIM, C. F. C.; SERRA, M. A. Instituições de ensino superior e desenvolvimento regional: o caso da região Norte do Paraná. Revista de Economia, Curitiba, v. 35, n. 3, p. 87-102, 2009.

ROMANIELLO, M. M.; AMÂNCIO, R.; CAMPOS, R. C. Análise da composição do capital social em uma estrutura organizacional cooperativa do sul de Minas Gerais. Organizações Rurais \& Agroindustriais, v. 14, n. 1, p. 15-27, 2012.

UNIVATES. Relatório das Atividades do Centro Universitário Univates no ano de 2013. Documento interno. Elaborado pelo Setor de Planejamento. 264 p.

YUSUF, S.; NABESHIMA, K. How universities promote economic growth. Washington: World Bank, 2007.

WAGNER, H. T.; BEIMBORN, D.; WEITZEL, T. How Social Capital Among Information Technology and Business Units Drives Operational Alignment and IT Business Value.

Journal of Management Information Systems, v. 31, n. 1, p. 241-272, 2014.

WEGNER, D.; MAEHLER, A. E. Desempenho de empresas participantes de rede interorganizacionais: analisando a influência do capital social e da capacidade absortiva.

Revista Gestão \& Planejamento, v. 13, n. 2, p. 191-211, 2012.

WESTLUND, H. Social capital in the knowledge economy: Theory and empirics. Springer Science \& Business Media, 2006. 
WOOLCOCK, M. Why and how planners should take social capital seriously. Journal of the American Planning Association, v. 70, p. 183-189, 2004.

ZHU, L.; THOMAS, B. School-Based Obesity Policy, Social Capital, and Gender Differences in Weight Control Behaviors. American Journal of Public Health, v. 103, n. 6, p. 10671073, 2013. 